\title{
A New Perspective: The Implication of Chaos/Complexity Theory in Language through Dichotomies
}

DOI: https://doi.org/10.47175/rielsj.v1i3.145

\begin{tabular}{|c|c|}
\hline $\begin{array}{l}{ }^{1,2} \text { Ph.D. candidate, } \\
\text { Department of English, Islamic } \\
\text { Azad University, Maybod } \\
\text { Branch } \\
{ }^{3} \text { English and Literature } \\
\text { Department, Faculty of } \\
\text { Languages and Arts, } \\
\text { Universitas Negeri Medan, } \\
\text { Indonesia } \\
{ }^{*} \text { zahrajafari.phd@gmail.com }\end{array}$ & $\begin{array}{l}\text { ABSTRACT } \\
\text { This study opens different points of view at chaos/complexity } \\
\text { theory (C/CT) which is still a new theory in second language } \\
\text { acquisition. Pro. Larsen-Freeman and her colleagues considered a } \\
\text { variety of characteristics, C/CT is known as nonlinear dynamics or } \\
\text { dynamical system theory that provides a framework for thinking } \\
\text { about change over time. Scientists claim that one can see not only } \\
\text { the laws of chaos but also those of order, through which a strong } \\
\text { explanation for how any collection of components will organize } \\
\text { itself and it can be generated in dichotomies. They attempt to } \\
\text { rationalize the behavior of large and complex systems, believing } \\
\text { they cannot be explained by usual rules of nature. } \\
\text { KEYWORDS } \\
\text { SLA; dynamic; Covid-19; chaos; complexity theory; nativization }\end{array}$ \\
\hline
\end{tabular}

\section{INTRODUCTION}

Science exists to elucidate the basic order underlying nature. The most valued explanations have taken the shape of cause and effect. For example, Newton was ready to find a cause for the movement of the stars in his simple laws of motion and theory of gravity. If scientists knew the positions and speed of all the particles in the universe, they would be able to predict the future for all time (Hall 1993).

Two major developments within the twentieth century have laid rest on such claims. The primary one was Heisenberg's uncertainty principle, introduced into quantum physics to explain the boundaries to which anything at the quantum level might be known certainly. The other was Chaos/Complexity Theory that was came up more recently with the invention of another quite unpredictability in nature.

Complexity theorists study more complex dynamical systems. It is important to recognize that complex does not mean complicated. A complex system is made up of a number of components and these components interact through their interaction pattern at different level emerges. The example that is often given in this regard is 'the birds' flock' meaning that the birds are on the ground pecking away, you walk by and they fly as a superorganism. They go up together, they do not bump into each other, there is no Captain Bird leading the way; they become a whole flock that has unique behavior by itself, they come back again and this process happens again and again. That is an example of a rather simple system but it is an emergent of the interaction between birds. This phenomenon as randomness was inherent.

\section{LITERATURE REVIEW}

\section{Some Features of Complex Nonlinear Systems}

Chaos/complexity scientists have identified more than ten characteristics of C/CT; namely they are complex, dynamic, nonlinear, adaptive, chaotic, unpredictable, self-organizing, 
feedback sensitive, open, and strange attractors which are fractal in shape.

By 'complex', Larsen-Freeman refers to the fact that an L2 system is influenced by a range of different factors both social and cognitive in nature affecting learning in different ways and at different times. As Gleick (1987) puts it, the study of 'chaos is a science of process rather than state, of becoming rather than being.' A complex system is 'dynamic' and 'open' in the sense that it is constantly changing. For example, the word "covidiot" or "coronaspeck" emerge into language by the spread of Covid-19 all over the world in 2020. $\mathrm{C} / \mathrm{CT}$ rejects the notion of a 'final state' in any language system (including the native speaker's), and in accordance with connectionist views of language, claims that small changes are forever ongoing. Learners' sub- system is also changing. For example, an English language beginner learned to greet people by saying 'how are you?'. This is what he thinks the right way to greet people or probably the only way. However, when he visits another country and hears people greeting by saying 'how are you doing? What's up!', then he may reconstruct his greeting system. A system is always in movement and never reaches complete equilibrium although there may be periods of relative stability. From the perspective of $\mathrm{C} / \mathrm{CT}$, therefore, there is no such thing as fossilization.

A complex system is 'adaptive' because it is responsive to the linguistic environment when grammar is 'a by-product of communication'. By 'self-organizing', Larsen-Freeman refers to the fact that change in one part of the system can trigger changes in other parts. A language system does not develop in linear ways hence different parts of the system develop at different rates and knowledge always needs to be retrieved.

Complex systems are also 'nonlinear'. A nonlinear system is one in which the effect is unequal to the cause. A cause in a linear system results in an effect of equal strength, while in a non- linear system a small routine action can cause an unpredictable large and sudden reaction that has been termed 'camel's back effect'. To point out a rolling pebble can trigger an avalanche, surprisingly a simple trigger which occurs all the time leads to a great effect in the system or to throw the whole system into a chaotic state. According to LarsenFreeman 'Chaos' refers simply to the period of complete randomness that complex nonlinear systems enter into irregularly and unpredictably. The onset of the randomness of complex nonlinear systems is in fact unpredictable. Now when the randomness occurring is predictable the moment is not exactly when it will occur. We know that avalanches are caused by sliding rock, however it is impossible to predict which rolling pebble will be the one to unleash a massive slide.

The main reason for the unpredictable behavior of complex systems is their sensitive dependence on initial conditions so that a minor change in initial conditions can have great implications for future behavior, in particular this phenomenon is known as 'the butterfly effect'. This metaphor as the main notion in chaos theory introduced by Edward Lorenz as a meteorologist having run a particular sequence although he decided to replicate it but what he found was in contrary to his expectations, therefore his results were radically different from his first outcome. When the butterfly fluttering its wings in a distant part of the world it will transform the local weather pattern next month. 'Tiny differences in input can quickly become overwhelming differences in output (Gleick 1987) or simply a small change or decision can cause very great consequences at a larger stage. The path that a dynamic system takes is often traced in space and is named an attractor. It receives this name because it is the pattern to which a dynamic system is attracted. A complex nonlinear system exhibits a special attractor altogether, one which was until recently unknown. Such a system features a 'strange attractor' because although its cycle repeats itself just like the frictionless pendulum, no cycle ever follows the precise same path or overlaps the other cycle. In simple words, the first language influences second 
language acquisition. For example, Korean students have an easier way to learn the word "camping" from Chinese students because Korean has similar pronunciation and the same meaning, but Chinese has different pronunciation and different character. The example that Larsen-Freeman finds the most helpful to illustrate a fractal is that of a tree. Trees come in all sizes and shapes; thus, it is impossible to predict the exact dimensions of a tree or where the branches (if any) will radiate from the trunk. Not all trees have left, and even if they did, we could not predict how many leaves there would be growing from which twigs on which branches, etc. Nonetheless, the mixture of arboreal shape, location, and behavior makes us unquestioningly recognize something as a tree.

\section{RESEARCH METHODS}

The randomness developed by complex systems has come to be called chaos. The study of chaos and therefore the study of the complex systems becomes an alternative to the linear reductionist thinking that has dominated science since Newton appears possible. Although such studies have originated in the physical sciences, researchers working in these areas believe that their theories have the potential for an immense impact on the more human sciences (Waldrop 1992:12-13). Chaos/Complexity Theory (C/CT) is still new in second language acquisition. Complexity theory aims to account for a way the interacting parts of a complex system produce to the system's collective behavior and the way such a system simultaneously interacts with its environment. (Larsen-Freeman and Cameron 2008). In other form, C/CT views all systems as complex and constantly adaptive involving interactions among the many components that comprise the system. C/CT has been applied to L2 acquisition by Larsen-Freeman.

\section{RESULTS AND DISCUSSION}

\section{Chaos/Complexity Theory and Dichotomies}

C/CT helps to shape the way we think, it invites us to interrogate 'dichotomies'. Dichotomy's thinking is useful not only in second language acquisition but also in human affairs more gently, specifically pondering about SLA through language vs. culture, product vs. process, grammar vs. communication, form vs. meaning, receptive skill vs. productive skills, and so forth. Dichotomies can be a helpful way to think and to learn about the respective characters of the honorable members of the pairs. One of the lessons that complexity theory reaches is the need to account for the non-duality of phenomena. When faced with dichotomies the learner has a number of possible options, either accept or refuse both members of a dichotomy, he can favor one over the other or similarly he can accept or reject one of them. Additionally, another option that C/CT encourages is to look at what connects the both sides together. $\mathrm{C} / \mathrm{CT}$ states that let us focus on the relationship between the two members of a dichotomous pair. In regard to the complexity theory perspective, there is a novel inspection to the emergence of dichotomy that is clearly a constituent in finding relationships and may lead to the development of new entity.

\section{Dichotomies and Second Language Learning}

The first dichotomy considers "grammar as a product and grammar as a process" that elucidates the dilemma of students learning a piece of point in the class and then going outside eventually they want to use that particular structure to their own purpose, Regrettably, they are not able to activate it for their own purposes. Indeed, there are plenty of reasons it occurs, according to Larsen-Freeman if grammar is contemplated more 
dynamically, more as a process rather than as a set of rules and more procedurally so the solution can be reached. The term "grammarring" is due to encourage this line of thinking, grammarring refers to an ability to utilize grammar structures accurately, meaningfully, and appropriately. It can be a dynamism of grammar in use, the unity is between not only the grammar as the product and also grammar as the process which becomes explicit when the language game is played while interacting with the language. In short, Grammaring emphasizes grammar as a dynamic process rather than a system of rules.

The rules are not assessed top-down however they emerge from the interaction of speakers using the language; even though playing the game, the language is learned and developed. The consistencies in language do not drive from rules or utilization but rather originates in language use; in other words, the regularity of grammar arise from interactions rather than constraint rules. Regularities are in different varieties and applicable to various stages; typically, they are provisional, ultimately heterogeneous. Notwithstanding, grammaring is the process by which language learners use grammar to compose messages through grammaticalizing or adding grammar to a consequence of words to create finer meaning distinctions.

The second dichotomy is between "form and meaning", the contrasting range of lexis and grammar. Here and now, it is more natural to realize the interconnection of lexis and grammar namely termed lexico-grammar. knowing a huge amount of grammatical and lexico- grammatical units makes them fluent in speech and writing, accordingly, these units are constructions which serve different functions. To illustrate, the phrase 'by the way' facilitates the function of the shift in the discourse topic, words, phrases, or clauses which are semi- lexicalized, and can be expandable or substitutable to extract formula from them. To clarify, there are conventional apologies for tardiness, including "I'm sorry to keep you waiting.", "I'm so sorry to have kept you waiting for Mr. X.", and "Sorry to keep you waiting all this time." As can be seen a specific frame, with some flexibility within it, can be learned as an apology. Traditionally, some of these phrases are easier lexicalized as rules of grammar, however, the huge number of grammatical rules are presented. Conversely consider the phrases 'all of a sudden' or 'so far so good', they are not predictable from the conventional rules. Equally the same phrases not only exist in other languages but also function in the same way, therefore they recognize and utilize the constructions in a variety of concrete contexts. Ultimately as the evidences suggest the learner extract the meaning and analyze the formula to induce the rules and regular patterns of the target language.

In usage-based linguistics and in usage-based acquisition first the learners learn the patterns, then abstract from the patterns or come through abstractions, later on, they apply to more than the individual occurrences from the recurrent sequences of words. Moreover, the patterns are not only conceptual as whole chunks in the learner's repertoire to add to the ability to speak fluently. Therefore, knowing these lexical phrases contributes a lot to the fluency but such patterns can be indispensable in writing.

The third dichotomy is 'between learner and learning' which may seem uncommon. Some linguists are interested in the process of language learning and they riveted on, however some are more interested in the learners and their differential success. Why all second language learners are not as successful as first language learners and account for the different levels of success achieved by them. Learning is stated to have occurred if the subject's performance on a post-test surpasses of their pre-test. The treatment is declared to have failed if no gain or negative gain is recorded. Remembering the avalanche effect; the unleashed avalanche from chaos theory, many pebbles may roll before the avalanche is set 
off. With regard to this theory; an investigative question arises; how will we know if our treatment is an ordinary pebble or an avalanche trigger with a simple pre-test or post-test?

Most teachers are aware of the fact that each individual learner is unique, not only it is not easy but also it is not advisable to generalize a learning process to all students from a complexity theory perspective. typically, it is realistic to separate the dancer from the dance and the learner from learning. Freeman explicates in her research of five Chinese learners of English how learners choose their focus, some opt for accuracy over fluency over time, while some prefer to be more fluent. Meanwhile; they had a common experience through the same teacher, the same books, the same assignments and the same syllabi. Each individual learner exhibits unique developmental trajectories over time, Learner variables overlap and communicate with others, proposed that we are not getting a true measure of a factor if we confine it from others. This would doubtlessly be the case if language acquisition may be a complex nonlinear process.

As Larsen-Freeman stated that dichotomies are beneficial but they have a deprivation. Likewise, C/CT which is holistic and deals with the whole; dichotomies obscure the connections between them although it looks for the connections. She recommends some possible implications for the above-mentioned dichotomies.

Some recursive and iterative activities are designed for learners to revisit the language many times, for instance, using a familiar language teaching technique called the 4-3-2 technique. The learners initially pair up and exchange a story for 4 minutes, next each find another partner and tell that new partner his stories in 3 minutes, and then he recures it for the new partner as a third time in 2 minutes. In the end the learner becomes not only more fluent due to repetition of the same story in less time but also more grammatical in the use of language. The cognitive resources are presumably freed up to attend to the form. In iterative use of language, it is neither repeating a piece of utterance or text each time nor recycling and coming back to the point where the learners are struggling with. It can be a pleasant pedagogical practice while paying attention is on the iteration to be transformative at the moment not recycling from time to time.

In regard to lexical grammar; iterative activities with some lexical grammatical constructions can be used. The idea is to create a situation where some the particular patterns are likely to be used frequently in a meaningful way. To illustrate, a pattern as 'an $\mathrm{X}$ needs verb+ing' as in 'my house needs painting'; is a very useful sequence. Imagine a situation where the pattern is going to occur, for example, the learners play calling-up an appliance store and asking their washer needs repairing and then having an opportunity to announce it; at first to the person who answers the phone, second to the person who transfers to the service department and for the third time the service desk transfer him to a particular technician who fixes that kind of washer. The notion of being able to assert that pattern over and over again in a meaningful way might assist learning of specific lexical grammatical pattern.

Finally, the third dichotomy is the union between learner and learning. Considering the affordance rather than input, the input suggests a one- way action from the environment to the learner whereas affordance is a relationship between the learner and the environment. A leaf on the forest floor, for example, is a part of the environment, it affords a shelter for some creatures, shade for others or food for still others. The leaf is identical but its affordances vary. In fact, it is the language learning opportunity that exists in the learner's linguistic environment. Shang Newgarden in 2012 defined affordances as opportunities for action in the eco-social environment that can motivate agents to act. Language resources developed from the experience afforded by the learners' perception of the environment. In 
other words, teaching does not cause learning, learners make their own paths. Learning another language is not about conformity to uniformity.

\section{CONCLUSION}

As described, the Chaos/Complexity Theory and the dichotomies underscore the importance of details as well as the whole. The language teachers are eagerly looking forward to an ample opportunity to use the language in a meaningful interaction, but learners can shape the interactions they participate in and they consciously choose what to learn. When focused on one side, must not lose sight of the other. The learners learn how the whole operates and simultaneously marks the details. It can be the small things that matter the most.

We need to consider SLA as both/and rather than either/or. In C/CT perspective, language use and language change, learner and learning, language and culture or grammar and communication are inseparable. C/CT and dichotomies help to increase the students feedback sensitivity, cultivate learners' ability rather than give deliberate teaching and last but not least, improve the interaction between students and teachers. And it encourages the connection between pairs through meaningful activity.

\section{REFERENCES}

Gattengno, C. (1987). The Science of Education. Part 1: Theoretical Consideration. New York: Educational Solution, Inc.

Gleick, J. (1987). Chaos: Making a New Science. New York: Penguin books.

Hall, N. (1993). Exploring Chaos: A Guide to the New Science of Disorder. New York: Norton and Company.

Horn, J. (2008). Human research and complexity theory. Educational Philosophy and Theory, v. 40, n. 1, p. 130-143, 2008.

Larsen-Freeman, D. \& Long, M. (1991). An introduction to second language acquisition research. London: Longman.

Larsen-Freeman, D. (1997). Chaos/complexity science and second language acquisition. Applied Linguistics, 18, 141-165.

Larsen-Freeman, D. (2000). Second language acquisition and applied linguistics. Annual Review of Applied Linguistics, 20, 165-181.

Larsen-Freeman, D. (2002). Language acquisition and language use from a chaos/complexity perspective. In C. Kramsch (Ed.). Language acquisition and language socialization: ecological perspective. (pp 34-46). London: CPI Bath.

Larsen-Freeman, D. (2003). Teaching language: From grammar to grammaring. Boston: Cengage.

Larsen-Freeman, D. (2007). On the complementarily of chaos/complexity theory and dynamic systems theory in understanding the second language acquisition process. Bilingualism: Language and Cognition, 10, 35-37.

Larsen-Freeman, D., \& Cameron, L. (2008). Complex systems and applied linguistics. Oxford: OUP.

Long, M. (1990). The Least a second language acquisition theory needs to explain. TESOL Quarterly 24: 649-66

Richards, J. C and Schmidt, R (2010). Language Teaching and Applied Linguistics. (4th. $\mathrm{Ed})$ 